\title{
Agile Development Process of a Web-Based Application to Improve Retention of Hispanic STEM Students
}

\section{Dr. Pablo Biswas, Texas A\&M International University}

Dr. Pablo Biswas received Ph.D. and M.S. in in Industrial Engineering from Louisiana State University, Baton Rouge, Louisiana, and B.S. in Mechanical Engineering Bangladesh University of Engineering and Technology, Dhaka, Bangladesh. He is an Assistant Professor of Engineering at Texas A\&M International University, Laredo, TX. Dr. Biswas's research interest is in supply chain management, inventory control, lean production systems, and information systems.

\section{Dr. Runchang Lin, Texas A\&M International University}

Dr. Runchang Lin received Ph.D. in Mathematics and M.A. in Statistics from Wayne State University, Detroit, MI, and M.S. in Computational Mathematics and B.S. in Mathematics from Tongji University, Shanghai, China. He is an Associate Professor of Mathematics at Texas A\&M International University, Laredo, TX. Dr. Lin's research interest is in Numerical Analysis and Applied Mathematics. He has published more than 20 articles in numerical analysis and education in peer reviewed journals. 


\title{
Agile Development Process of a Web-Based Application to Improve Retention of Hispanic STEM Students
}

\begin{abstract}
This study describes the application of Agile system development process and its accomplishments on a web-based Teaching Assistant System (ViTAS). The ViTAS is developed to improve the retention rate of the students in a Hispanic-Serving Institution. In particular, this project focuses on the Agile system development process, which is a group of software development methodologies based on iterative, interactive, and incremental development, where requirements and solutions evolve through collaboration between self-organizing and crossfunctional teams. Also, the teaching assistant system is developed as a digital warehouse of homework assignments and students' work in STEM courses. This system provides a homework assignments grading system for the students' as well as instructors in STEM field and to provide an interactive learning environment outside the class for the students. Using ViTAS, students are able to submit the assignments online, to engage in anonymous peer review, and to discuss with their peers. The students grading their peer assignments are beneficial as during the process of grading other's work, the students get the opportunity to learn/review their own work/mistakes.
\end{abstract}

Key words: Agile development, virtual teaching assistant system, anonymous peer review.

\section{Introduction}

In the United States, the Hispanics are the fastest-escalating and youngest ethnic group. It is projected that the Hispanics will comprise 31 percent of the U.S. population by the year 2060 and will become the largest ethnic group by then ${ }^{29}$. Nevertheless, low enrollment of Hispanics in STEM disciplines and lack of professionals in STEM-specific careers is a major concern to many. As a major Hispanic-Serving Institution (HSI) in southern Texas, _ University has been engaged in providing quality education in STEM disciplines to Hispanic and other minority communities. The university intends to reduce the class drop rate for early college education in engineering, mathematics, and physics curriculums. According to the enrollment in Fall 2013 the university has more than 7,431 students who are studying in various degree programs of arts, business, education, engineering, nursing, and sciences. The enrollment data presented in Table 1 , indicates that the majority of the students are Hispanic and among them almost $50 \%$ are firstgeneration of college students. Table 1 represents the enrollment data based on students' profiles from academic year 2009 to 2014. Therefore, a significant number of first-generation college students do not get the academic support from their family members [Dennis et al. ${ }^{10}$ ].

Crisp et al. ${ }^{9}$ examined the demographic, pre-college, environmental, and college-factors that impact students interests in and decisions to earn a science, technology, engineering, or mathematics (STEM) degree among students attending a Hispanic Serving Institution (HSI). Results indicated that Hispanic students were well represented among STEM majors and students' decisions to declare a STEM major and earn a STEM degree were uniquely influenced by students' gender, ethnicity, SAT math score, and high school percentile. Cole and Espinoza ${ }^{7}$ used a longitudinal sample of 146 Latino students in science, technology, engineering, and mathematics majors, to examine factors that affect their academic performance. The study suggested that Latino students perform better academically when they have cultural congruity 
within their chosen academic major. Table 2 shows the STEM discipline enrollment from academic year 2009 to 2014. As the enrollment is increasing in STEM discipline year by year, still more enrollment is expected among the Hispanic students. Based on the scenarios and the literatures, it is observed that the successes of the Hispanic students especially in Science, Technology, Engineering, and Mathematics (STEM) fields depend on the support of their teachers and mentors.

Table 1. Enrollment data based on students’ profile*

\begin{tabular}{|l|c|c|c|c|c|c|c|c|c|}
\hline Academic Year & \multicolumn{2}{|c|}{ FY 2009-10 } & \multicolumn{2}{|c|}{ FY 2010-11 } & \multicolumn{2}{|c|}{ FY 2011-12 } & \multicolumn{2}{|c|}{ FY 2012-13 } & FY 2013-14 \\
\hline Students' Profile & $\begin{array}{c}\text { Fall } \\
\mathbf{0 9}\end{array}$ & $\begin{array}{c}\text { Spring } \\
\mathbf{1 0}\end{array}$ & $\begin{array}{c}\text { Fall } \\
\mathbf{1 0}\end{array}$ & $\begin{array}{c}\text { Spring } \\
\mathbf{1 1}\end{array}$ & $\begin{array}{c}\text { Fall } \\
\mathbf{1 1}\end{array}$ & $\begin{array}{c}\text { Spring } \\
\mathbf{1 2}\end{array}$ & $\begin{array}{c}\text { Fall } \\
\mathbf{1 2}\end{array}$ & $\begin{array}{c}\text { Spring } \\
\mathbf{1 3}\end{array}$ & Fall 13 \\
\hline Total Students & $\mathbf{6 4 1 9}$ & $\mathbf{6 0 8 8}$ & $\mathbf{6 8 5 3}$ & $\mathbf{6 5 4 4}$ & $\mathbf{7 0 3 7}$ & $\mathbf{6 5 2 9}$ & $\mathbf{7 2 1 3}$ & $\mathbf{6 6 2 4}$ & $\mathbf{7 4 3 1}$ \\
\hline Female & 3844 & 3678 & 4076 & 3955 & 4209 & 3910 & 4243 & 3922 & 4347 \\
\hline Male & 2575 & 2410 & 2777 & 2589 & 2828 & 2619 & 2970 & 2702 & 3084 \\
\hline Concurrent HS & 889 & 625 & 947 & 699 & 997 & 898 & 1189 & 936 & 1236 \\
\hline $\begin{array}{l}\text { First-Time in } \\
\text { College }\end{array}$ & $\mathbf{7 1 3}$ & $\mathbf{6 3}$ & $\mathbf{8 6 6}$ & $\mathbf{5 0}$ & $\mathbf{6 9 4}$ & $\mathbf{5 3}$ & $\mathbf{8 3 7}$ & $\mathbf{4 7}$ & $\mathbf{8 3 1}$ \\
\hline Hispanic & $\mathbf{5 8 2 2}$ & $\mathbf{5 5 3 5}$ & $\mathbf{6 2 4 0}$ & $\mathbf{6 0 0 2}$ & $\mathbf{6 4 9 7}$ & $\mathbf{6 0 2 9}$ & $\mathbf{6 7 0 1}$ & $\mathbf{6 2 0 0}$ & 6916 \\
\hline Undergraduate & 5315 & 5024 & 5823 & 5526 & 6099 & 5655 & 6384 & 5887 & 6585 \\
\hline $\begin{array}{l}\text { First-Generation } \\
\text { Undergrads }\end{array}$ & $\mathbf{2 4 3 9}$ & $\mathbf{2 3 9 2}$ & $\mathbf{2 5 5 9}$ & $\mathbf{2 6 6 9}$ & $\mathbf{3 2 4 9}$ & $\mathbf{3 5 5 5}$ & $\mathbf{3 7 9 7}$ & $\mathbf{3 7 7 1}$ & $\mathbf{4 0 0 8}$ \\
\hline
\end{tabular}

* The data collected from the office of Institutional Research at__University.

Table 2. Enrollment statistics in STEM Disciplines ${ }^{*}$

\begin{tabular}{|lcccccccccc|}
\hline \multicolumn{1}{|c}{ STEM Disciplines } & $\begin{array}{c}\text { Spring } \\
\mathbf{0 9}\end{array}$ & $\begin{array}{c}\text { Fall } \\
\mathbf{0 9}\end{array}$ & $\begin{array}{c}\text { Spring } \\
\mathbf{1 0}\end{array}$ & $\begin{array}{c}\text { Fall } \\
\mathbf{1 0}\end{array}$ & $\begin{array}{c}\text { Spring } \\
\mathbf{1 1}\end{array}$ & $\begin{array}{c}\text { Fall } \\
\mathbf{1 1}\end{array}$ & $\begin{array}{c}\text { Spring } \\
\mathbf{1 2}\end{array}$ & $\begin{array}{c}\text { Fall } \\
\mathbf{1 2}\end{array}$ & $\begin{array}{c}\text { Spring } \\
\mathbf{1 3}\end{array}$ & $\begin{array}{c}\text { Fall } \\
\mathbf{1 3}\end{array}$ \\
\hline Biology & $\mathbf{2 7 0}$ & 342 & 313 & 398 & 378 & 448 & 401 & 462 & 413 & 485 \\
\hline Chemistry & 18 & 22 & 19 & 34 & 30 & 39 & 41 & 42 & 33 & 41 \\
\hline Environmental Science & 9 & 15 & 14 & 15 & 19 & 19 & 18 & 9 & 7 & 3 \\
\hline Physical Science & 90 & 34 & 27 & 22 & 10 & 9 & 8 & 10 & 2 & 2 \\
\hline Other Sciences & 33 & 15 & 8 & 14 & 15 & 16 & 11 & 14 & 12 & 11 \\
\hline Pre-Engineering & 20 & 33 & 47 & 117 & 102 & 114 & 113 & 150 & 135 & 191 \\
\hline Systems Engineering & 6 & 21 & 28 & 51 & 53 & 67 & 66 & 86 & 86 & 115 \\
\hline Mathematics & 11 & 123 & 120 & 141 & 129 & 131 & 107 & 94 & 84 & 108 \\
\hline Total & $\mathbf{4 5 7}$ & $\mathbf{6 0 5}$ & $\mathbf{5 7 6}$ & $\mathbf{7 9 2}$ & $\mathbf{7 3 6}$ & $\mathbf{8 4 3}$ & $\mathbf{7 6 5}$ & $\mathbf{8 6 7}$ & $\mathbf{7 7 2}$ & $\mathbf{9 5 6}$ \\
\hline
\end{tabular}

Due to lack of proper education in the high school level, the incoming freshmen at TAMIU have faced difficulty to deal with college level mathematics, science, and engineering. Therefore, a significant class drop rate is observed in such lower division courses. The need for improving student success in early college education can be determined by the high class drop rate in lower division courses such as college algebra, business mathematics, trigonometry, etc. According to the undergraduate curriculum, all undergraduate students of TAMIU are required to take college algebra or equivalent core curriculum in their degree programs. The drop rates in lower division mathematics courses are not uncommon. 
The homework grading system for any class in STEM field is insufficient for interaction between professors and students. Though the professors have office hours available to answer the students' questions, but the students may not be utilizing these hours because of their full-time or part-time work schedules or other engagements. Therefore, given the failure to maintain an open communication, the students repeat the similar mistakes in the examinations as they did in the homework. Such failures in exams and homework drive struggling students to drop the class before completion.

\section{Literature review}

Researchers found an encouraging correlation between homework activities and the class drop rate. Cooper et al. ${ }^{8}$ conducted a research where 709 Students and their parents, and 82 teachers completed a questionnaire concerning amount of homework assigned by teachers, portion of assignments completed by students, and attitudes about homework. Upon collection of student achievement measures, the authors found weak relations between the amount of homework assigned and student achievement, and positive relations between the amount of homework students completed and achievement, especially at upper grades (6-12). Bempechat ${ }^{3}$ obtained research on parental involvement in student homework, and found that parents involve themselves in student homework because they believe that they should be involved, believe that their involvement will make a positive difference, and perceive that their children or children's teachers want their involvement. Unfortunately, the first-generation college students fail to get that at TAMIU.

Moreover, researchers found that homework and assignments play constructive role in the course performance of all levels of students. Ryan and Hemmes ${ }^{27}$ studied the effects of the contingency for submission of homework assignments and found that homework submission was not maintained when the only consequences were instructor-provided feedback and expectation of improved quiz performance. Recently, Schmitz and Perels ${ }^{28}$ studied aims at enhancing math learning and general self-regulation by supporting daily self-regulated learning during math homework. The authors used standardized diaries as a self-monitoring tool to support selfregulatory behavior. Eren and Henderson ${ }^{11}$ studied examined the effect of homework on math, science, English and history test scores for eighth grade students in the United States and found find that math homework has a large and statistically meaningful effect on math test scores. PytlikZillig et al $^{25}$ examined two frequently-used discussion protocols that were as part of a program to implement teaching cases in undergraduate that involved synchronous face-to-face (FTF) and asynchronous computer-mediated (CM) discussion taking place outside of class. They found both CM and FTF discussion related to higher cognitive-affective engagement with the cases than the control condition and the CM discussion condition was associated with higher cognitive-affective engagement than FTF discussion. In contrast, FTF discussion, but not CM discussion, was associated with higher-than-control-condition case analysis ability at the end of the semester. Katz et al. ${ }^{17}$ employed self-determination theory as a theoretical framework for investigating the role of parents in the quality of the motivation that students adopt towards homework. The findings highlight the role of type of parents' involvement with their children's homework in the children's motivation toward homework, and of parents' own type of motivation for this task in the quality of their involvement. Gebru and Phelps ${ }^{16}$ studied the effects of student response systems (clickers) versus online homework on students' long-term retention of General Chemistry I course material. Their work suggested that treatments that enhance student's 
feedback may increase student retention in the course sequence with no loss in learning. Xu and $\mathrm{Wu}^{31}$ observed experiential models of variables suggested to predict homework management at the secondary school level.

According to previous research, the students who stayed in the classroom through the semester, and submitted homework regularly have better grades. Also, the lower is the homework submission, the lower the grads at the end of the semester. Table 3 represents the homework performance data and course grades in several freshman and sophomore level courses in STEM field from 2009 to 2013. Based on the course grade with homework performance, it is found that students who earned an "A" submitted almost all assigned homework during the semester. On the other hand, if the students submitted only $63 \%$ of their homework, chances of their success in those courses were little. Another observation states that homework score is also correlated with the final course grade. For example, when a student earned an " $A$ " on the course, his/her homework score was above 90 on average. Similar conclusion can be made for those students who scored "B," “C," "D," and "F." Many TAMIU students work very hard in their courses, yet a regular class time may not be sufficient to create and interactive environment to address all the problems that students may have for the course. This situation is true for the classes where the student number is greater than 40. Therefore, innovative methods must be devised and implemented to improve the retention and class performance in mathematics, engineering, and physics.

Table 3. Correlation between homework and grads ${ }^{*}$

\begin{tabular}{lccccc}
\hline Final Grade & A & B & C & D & F \\
\hline Number of students & 1666 & 1882 & 2000 & 984 & 1138 \\
Homework submission rate (\%) & 95 & 88 & 86 & 78 & 63 \\
Average homework score & 92 & 84 & 73 & 64 & 49 \\
\hline
\end{tabular}

Biswas and $\mathrm{Lin}^{4}$.

\section{Web-based application for homework submission}

Many researchers have found that incorporating new technologies to establish great relationships among the professor and students are a part of the interactive teaching. Warschauer and Healey ${ }^{30}$ provided an overview of current teaching practices and research related to the uses of computers in the language classroom. $\mathrm{Lu}$ and $\mathrm{Bol}^{20}$ found that peer review has become commonplace in composition courses and the results of their research from both semesters showed that students participating in anonymous e-peer review performed better on the writing performance task and provided more critical feedback to their peers than did students participating in the identifiable epeer review. Lowes et al. ${ }^{19}$ studied the online professional development courses with the discussion forums and the study described the insights into the effectiveness of the course design and facilitation and correlated these with participant satisfaction, and argues for using a combination of methods when studying discussion forums in online courses. Similar studies are carried out by Park and Bonk ${ }^{22}$ with applied synchronous learning communication in education.

According to the previous findings, a need for an interactive application that will serve as the active communication port between professors and the students of TAMIU outside the class 
period became very crucial. Also, the need to improve early college students' course performance in mathematics, engineering, chemistry, and physics became the motivation to develop a web-based homework submission, feedback, and review system. Biswas and $\operatorname{Lin}^{4}$ and Biswas et al. ${ }^{5}$ developed a homework management system through which the students are able to submit homework assignments outside of class and are assigned to grade their peers anonymously. This initiative of on-line homework management systems allowed students to get the chance to learn/review their own work/mistakes. The next sections present the functionality of the Virtual Teaching Assistant System (ViTAS), implementation of ViTAS, performance of the students after using the system, and student feedback about ViTAS for future improvements.

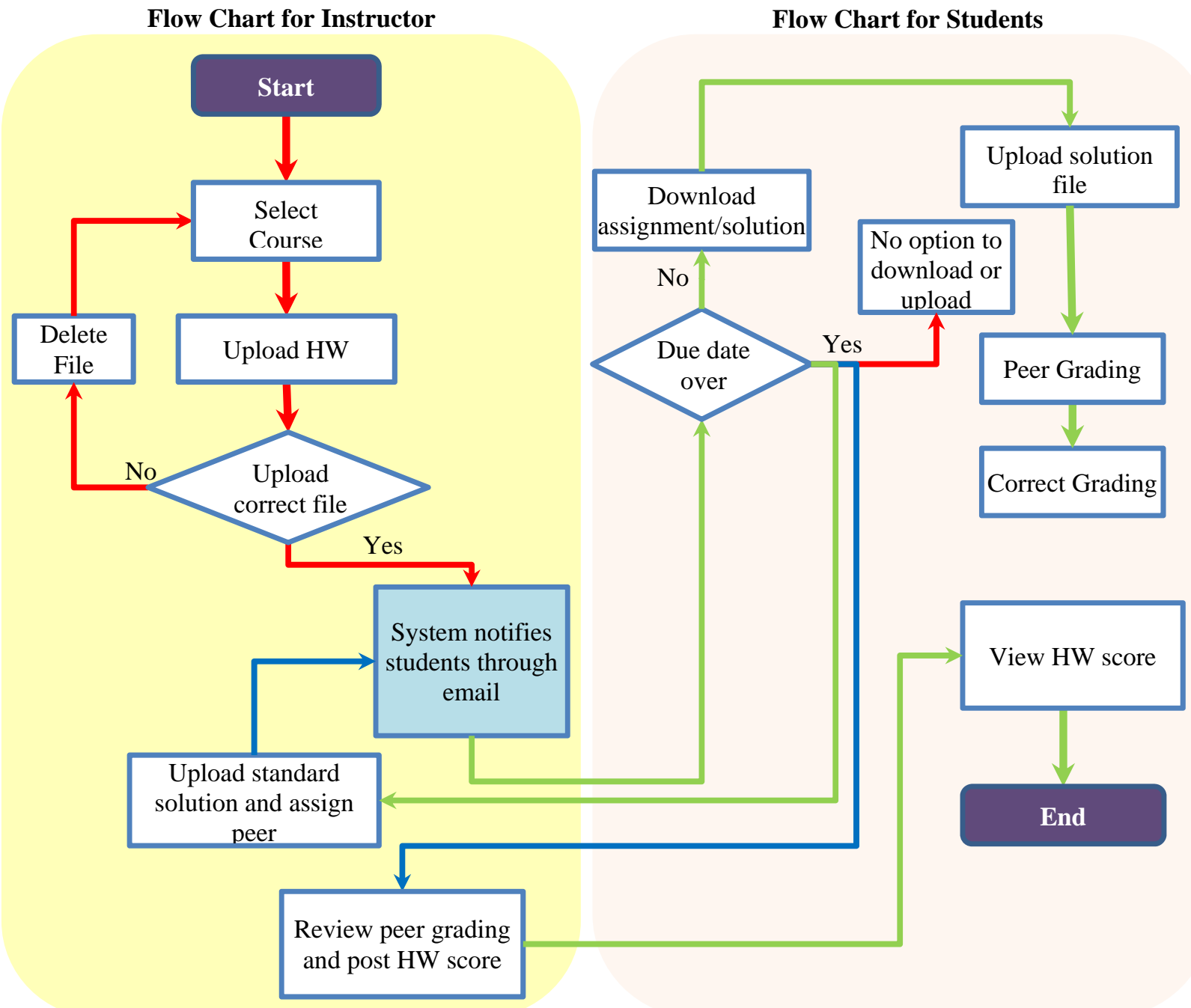

Figure 1. Operational flow chart for Virtual Teaching Assistant System

\section{(a) System for instructors}

The system for instructors consists of four major functionalities, they are (i) view class rosters, (ii) view homework, (iii) upload homework, and (iv) peer assignment. The view class rosters page consists of the list of courses and the details of all student enrollments in all courses that an instructor is teaching. 
In view homework page the instructor is able to see the homework assignments he posted for the students. Also, in this page an instructor can check the students' homework submissions by clicking "View Students' Homework" button. In this page, the instructors review and finalize the grading for the students for any homework assignment. In the upload homework page, instructors upload the homework assignments and their due date for the students based on the courses he/she is teaching. Whenever an instructor uploads a homework assignment for a particular course, the student automatically receives the notification of the homework through their email addresses. If the instructor reassign the due date, the ViTAS sends the change notification for that particular homework assignment.

Finally, the peer assignment page allows the instructors to upload solution to the homework assignments he/she posted earlier and this functionality is used after the due date of homework assignments. Also, the instructors assign the peer homework solutions uploaded by the students on or before the due date, to each student automatically by clicking the "Assign Peer" button. Before the peer assignment by the instructor is due, the ViTAS sends a reminder to the instructor through email.

\section{(b) System for students}

After authentication to the ViTAS system, a student can see the list of courses he/she is enrolled in a particular semester and three buttons (i) view student's submission, (ii) view assignment and upload solution, and (iii) peer grading. In view homework page, the student views the dropdown menu of courses and a table consists of downloadable Link of the homework he/she uploaded based on the course list. Also, the student views the points he/she received all homeworks after the grade has been finalized by the instructor.

The upload solution page provides the students to download the homework assignment for a course and upload the solution by the due date. After the due date the homework assignment does not appear in the dropdown list. Also, when a student uploads a file for homework assignment, the file is renamed by the ViTAS system automatically using random number, which makes the peer grading anonymous.

Finally, when the instructor assigns the peer to the students after the submission due date, the student visits the peer grading page and download the peer homework assignment including the correct solution posted by the instructor. As the name of the peer solution is a random number (generated by the ViTAS), makes the students remain unaware of their peer. Also, the students can view the maximum points possible for any assignment and grade their peer though this page. After grading the students can comment on the mistakes their peers made, which are visible to their peers in view student's submission page. The next section discusses the improvements made based on the feedback received.

\section{Agile methodology in ViTAS improvement}

In system development process, several methodologies of system development life cycles have been followed by the development teams. These are waterfall model, rational unified process, "Vee" process model, spiral model, agile development, etc. Nowadays, the typical system 
development industries have not been so great while they have to deliver the working system application in time and within the budget. It is widely reported that among $80 \%$ of all system development projects fail because of lack of end-user involvement, poor requirement analysis, unrealistic schedules, lack of change management, testing and inflexible and bloated processes $\left[\mathrm{Cohn}^{[7]}\right.$, Martin $\left.^{[24]}\right]$. In agile system development process addresses these issues that make system development processes more successful. Also, in the agile development process, a minimal documentation is required to start the process as users, system analyst, developers, team leader, quality assurance analyst, and database administrator work together as a team.

Recently, the agile development process got lot of attention to the researchers in the area of information technology. Procter et al. $^{24}$ used a case study of a project to create a Web 2.0-based, Virtual Research Environment (VRE) for researchers to share digital resources in order to reflect on the principles and practices for embedding eResearch applications within user communities using agile development. Garcia et $a l^{13}$ provided a set of guidelines to develop knowledge-based Process Asset Libraries to store system engineering best practices, implemented as a wiki and improves the use of agile processes. Greer ${ }^{15}$ addressed a range of research areas including the application of agile methods to safety critical system development, the relationship of agile development with user experience design and how to measure flow in lean system development. Similar research is done by Gary et al. ${ }^{14}$ on the basis of agile development process. Ferreira et al. ${ }^{12}$ reported in detail on one observational study of a mature Agile/Scrum team in a large organization, and their interactions with the user-experience designers working on the same project. The authors also explained how multi-cultural teams work together in agile environments. Based on the previous research and working experiences in agile environment, the agile methodology is used for the development of both ViTAS 1.0 and ViTAS 2.0 applications.

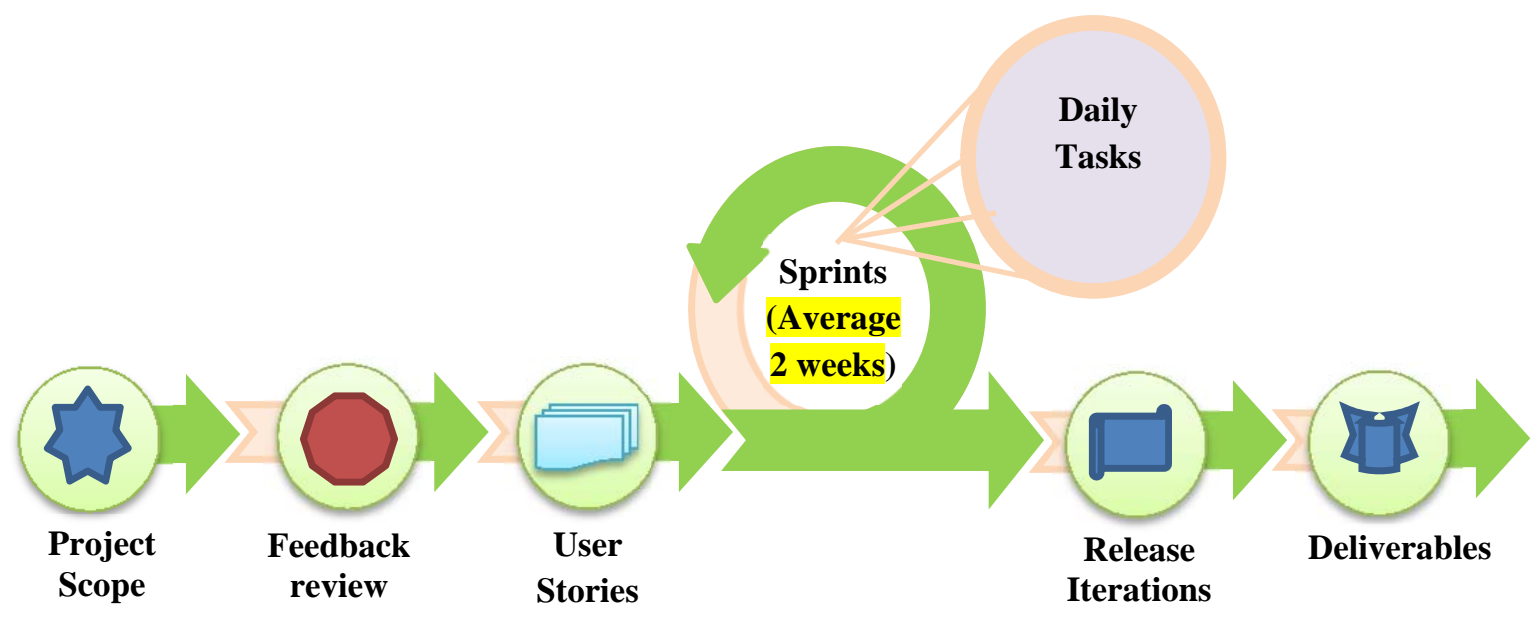

Figure 2. Agile development life cycle

\section{Agile development process for improvements of ViTAS}

Agile system development is a group of software development methodologies based on iterative and incremental development, where requirements and solutions evolve through collaboration between self-organizing, cross-functional teams and most importantly the stake holders/users. Figure 2 represents the Agile development life cycle. Based on $\mathrm{Cohn}^{6}$ and $\mathrm{Ambler}^{1}$, the agile 
development process has the following stages in the system development project which was followed during the development of ViTAS 1.0 and ViTAS 2.0 [Biswas et al. ${ }^{5}$, Biswas and Lin $^{4}$ ]. The next sections discuss the further improvement that has been made for ViTAS.

\section{The prospect for improvements}

In spring 2012, ViTAS 1.0 was implemented, which is a web-based application, and provides the student and the professors at TAMIU an interactive communication baseline outside of class. The students will upload their homework solutions given by the professor on a particular class such as college algebra, business math I and II, general physics, principal of electrical engineering, etc. Based on the feedback from the users, ViTAS 2.0 was developed by improving the system functionality and making it more user-friendly. In the survey of ViTAS, a question was asked "What was most beneficial to you about using ViTAS." The response from the users (students and instructors) provided a few insights to improve the ViTAS, which are presented below:

\section{Instructor's suggestion:}

- When an instructor enters ViTAS, have a one page summary by class of what has been done and what solutions have been posted. This would make it easier to see what needs to be done.

- An instructor needs a summary of what each student has done so that he/she can quickly see who has graded assignments and who had not. Easy access to this information is really important if extra points are awarded for grading.

- There needs to be a grade book for ViTAS. It should list each student name/ID and provide for each assignment the student's grade given by the instructor and grade given by the student grader, and whether this student had graded someone else's assignment.

\section{Students' suggestion:}

- Mobile version of the site and also a tablet version where we can upload homework from those devices.

- On peer grading, the comment box can be improved to fit in the box and word wrap.

- Remove the limitation of file size.

- When submitting grades I want to be able to see what will appear on other student's computer. I was confused when I resubmitted a grade.

- ViTAS needs to accept multiple file formats such as pdf, docx, jepg, doc, etc.

- ViTAS can be improved by storing solutions throughout the semester.

- Upload multiple files for a single homework assignment submission.

After reviewing the stability and the feedback of the system, the improvement of ViTAS was necessary to add more functionality and to make further user-friendly, so that the students and the instructors can solve the problems by themselves instead of the administrators.

\section{Initial planning for improvements}

In the initial plan of the ViTAS 3.0 development, few important aspects is considered such as hiring the appropriate personnel (graduate assistants), improving the functionalities of ViTAS, providing access outside of the campus, password recovery, adding a sub-system for interdepartmental conferences, and making more user-friendly. Based on the feedback from the 
users of ViTAS 1.0 and 2.0, the user stories/functional requirements are considered to develop the user stories and their required task to complete the development.

\section{User stories and required tasks development and prioritization}

In agile development, it is most important to accumulate the requirements, prioritize them and construct the iterations to complete the development processes. Therefore, in this phase of the development, all experienced users and development team members of ViTAS discussed the design issues and requirements in several meetings based on the use of ViTAS. Table 4 shows the stories with their points and priorities that are generated from the constructive.

Table 4. Sample list of ViTAS improvement stories with priorities and points

\begin{tabular}{|c|c|c|c|c|}
\hline $\begin{array}{l}\text { Story } \\
\text { Number }\end{array}$ & Title & Owner & Priority & Point \\
\hline TFS 1 & Remove limitation of uploaded and downloaded file size & Developer & $* * * * *$ & 1 \\
\hline TFS 2 & $\begin{array}{l}\text { Create SSIS packages for assigning HW assignment } \\
\text { based on the due date automatically }\end{array}$ & $\begin{array}{c}\text { Database } \\
\text { Administrator }\end{array}$ & $* * * * *$ & 8 \\
\hline TFS 3 & $\begin{array}{l}\text { Create SSIS packages for assigning peer assignment and } \\
\text { make solution available to the students based on the due } \\
\text { date automatically }\end{array}$ & $\begin{array}{l}\text { Database } \\
\text { Administrator }\end{array}$ & $* * * * *$ & 8 \\
\hline TFS 4 & $\begin{array}{l}\text { Create summery page for instructors based on the } \\
\text { courses }\end{array}$ & Developer & $* * * *$ & 5 \\
\hline TFS 5 & $\begin{array}{l}\text { Create grade books for ViTAS that will contain all } \\
\text { grades with the homework for any course }\end{array}$ & Developer & $* * * * *$ & 13 \\
\hline TFS 6 & $\begin{array}{l}\text { Semester dropdown menu needs to be added in every } \\
\text { module to maintain the historical use of ViTAS }\end{array}$ & Developer & $* * * * *$ & 20 \\
\hline TFS 7 & $\begin{array}{l}\text { Students will be able to view the courses he/she is } \\
\text { registered for a particular semester }\end{array}$ & User & $* * * * *$ & 5 \\
\hline TFS 8 & Make ViTAS accept multiple file format for uploading & User & $* * * * *$ & 8 \\
\hline TFS 9 & $\begin{array}{l}\text { Upload multiple files for a single homework assignment } \\
\text { submission }\end{array}$ & User & $* * * * *$ & 5 \\
\hline TFS 10 & $\begin{array}{l}\text { Student will be able to view his/her final grading for } \\
\text { each homework of each course }\end{array}$ & User & $* * * * *$ & 3 \\
\hline
\end{tabular}

" It is assumed that $* * * * *$ is the highest priority and * is the lowest priority.

After the stories are generated based on the discussion, the team members pointed them using the number sequence such as $1,2,3,5,13,20,40,100$, based on Cohn's ${ }^{[6]}$ suggestion. A lot of agile development teams throughout the United States assumed that 1 point is equivalent to 3 to 5 hours of work for a particular stories/task. Therefore, if a story has 5 points, it is estimated to be completed in 15 to 25 hours for a person based on his/her experience level. In the process of the 
ViTAS development, professors along with a graduate student from MIS department of TAMIU are selected as the development team members. Also, the professors and students are the userexperience design members. Initially, the entire development team generated 24 user stories, but as the development progressed, the more stories are added based on the new/changed requirements.

\section{Constructive iterations/sprints for improvements}

The constructive iteration phase in agile development process follows Just-in-Time technique, which means "the right stories, during the right time, to the right person, and in the exact amount." The agile development process addresses the issues during development or coding phase that can be fixed right away as the amount of work is not overloaded per iteration and per person. Another important and most popular aspect of agile development is testing, testing, and testing in each step of the constructive iteration phase.

After completing the story development session in iteration 0, the constructive iterations are generated based on the priorities of the stories. For example, in Iteration 1 of the ViTAS 2.0 development consists of story numbers from TFS 1 to TFS 6 and all iterations have a length of two weeks. These iterations consist of development, testing, bug detections and rework, integration, and user acceptance testing.

In this phase of ViTAS development, the stories are uploaded to Microsoft Team Foundation Server (TFS) and arranged according to their priority. TFS makes the development process easier by tracing the bottleneck stories (the incomplete stories of previous iterations) and the bugs/defects related to the stories. The agile development process insists the team members to meet daily for 10 to 15 minutes and share their progresses, road-blocks, suggestions regarding the story functionality, bugs, etc. This is another way to bring an enjoyable atmosphere into the development environment. Based on this criterion, the ViTAS development team meets every two days interval to make sure every process in the application is progressing smoothly.

\section{Release iterations of ViTAS and deliverables}

In release iteration it is important to test all the permission issues, network issues, and firewall issues, so that when the system is being used by the users it works perfectly. The server that is been setup can handle 75 users at any point in time without overloading it. Also, the web link that is generated to use this application only be available to the users from the TAMIU computer labs. The front end of the system is developed in the ASP.Net platform and Visual Basic.Net language with SQL server at the backend. This system will continue to improve its functionalities as the feedback will be received from the end users. The web page of the ViTAS is shown in Figure 3. As most of the improvements took place in this process is in the backend of the system, as a result, the other functionality pages are not presented in this research. 


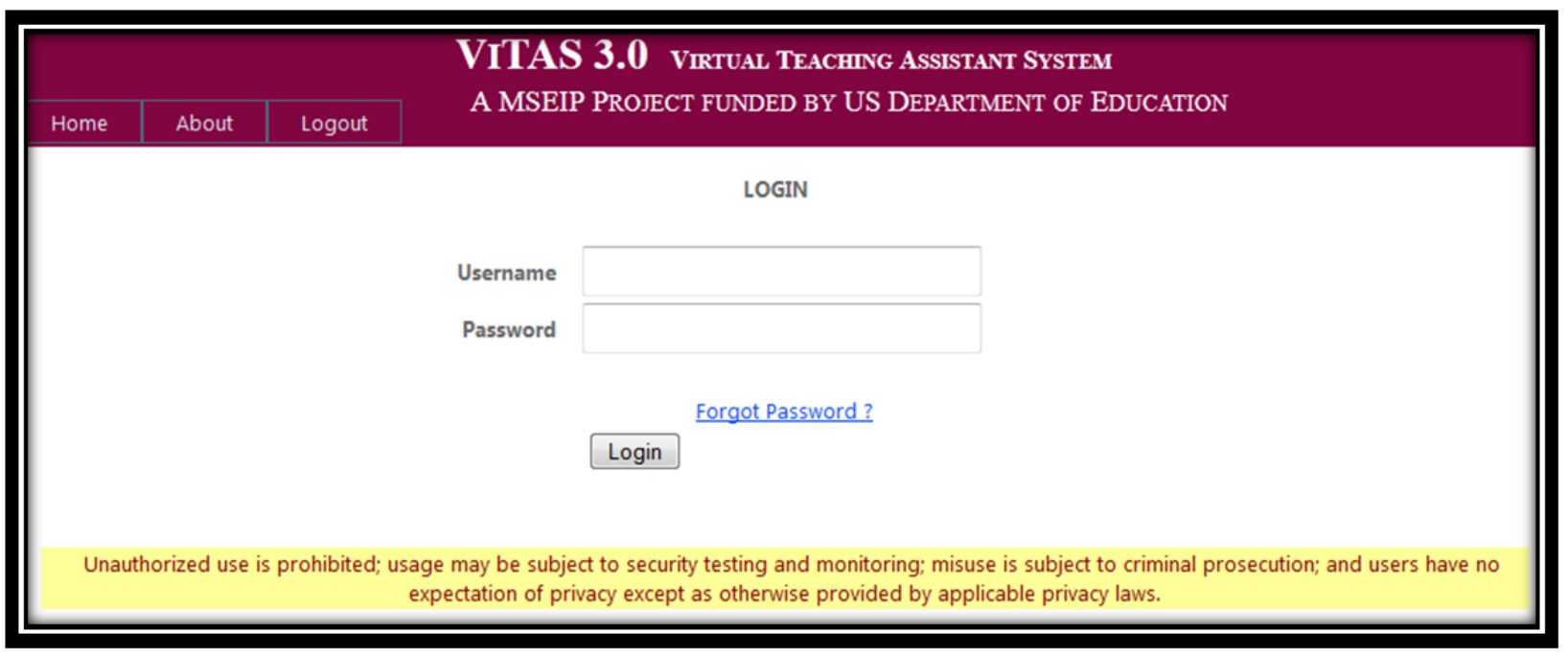

Figure 3. Main web page of Virtual Teaching Assistant System

\section{Implementation of ViTAS and students' survey}

The ViTAS 1.0 system was introduced in spring 2012 in 10 courses in the different level of STEM courses. Initially, the ViTAS was not available to the students outside the TAMIU campus because of security issues of the Office of Information and Technology. Still the students adopted the system gladly and made great effort to use the system in homework assignment, submission, and peer grading. Based on the feedback, the ViTAS 2.0 was introduced in Summer I and II 2012 and carried out to Fall 2012 for 3 and 11 courses [Table 5] and the ViTAS 3.0 was implemented in Spring 2013 for 9 courses [Table 6].

Table 5. Implementation of ViTAS in STEM courses in Fall 2012

\begin{tabular}{llr}
\hline \multicolumn{1}{c}{ Course Number } & \multicolumn{1}{c}{ Course Name } & Enrollment \\
\hline MATH 1314 - 101 & College Algebra LC J & 51 \\
MATH 1314 - 103 & College Algebra & 55 \\
MATH 1325 - 101 & Business Math II & 25 \\
\hline MATH 1342 - 162 & Introductory Statistics & 64 \\
MATH 1350 - 102 & Fundamentals of Mathematics I & 35 \\
MATH 2413 - 103 & Calculus I & 39 \\
MATH 2415 - 101 & Calculus III & 50 \\
\hline PHYS 1301 - 101 & General Physics I & 76 \\
ENGR 1202 - 101 & Foundations of Engineering II & 14 \\
\hline ENGR 2303 - 102 & Eng Mechanics: Statics \& Dynamics & 23 \\
\hline SENG 3301 - 102 & Engr Project Management \& Proposals & 21 \\
Total in Summer & & $\mathbf{4 5 3}$ \\
\hline
\end{tabular}


Table 6. Implementation of ViTAS in STEM courses in Spring 2013

\begin{tabular}{llr}
\hline \multicolumn{1}{c}{ Course Number } & \multicolumn{1}{c}{ Course Name } & Enrollment \\
\hline MATH 1314- 204 & College Algebra & 38 \\
MATH 1325- 201 & Business Math II & 26 \\
MATH 1342- 201 & Introductory Statistics & 59 \\
MATH 3360- 202 & Statistical Analysis & 31 \\
MATH 5360- 262 & Partial Differential Equations & 6 \\
MATH 5370- 262 & Mathematical Modeling & 6 \\
PHYS 2325- 201 & University Physics I & 55 \\
ENGR 2372- 202 & Intro Design Experiments & 24 \\
SENG 3350- 201 & Prod Planning and Control & 20 \\
Total in Summer & & $\mathbf{2 6 5}$ \\
\hline
\end{tabular}

"No system is perfect," therefore the ViTAS is not perfect either. There were several drawbacks with ViTAS 1.0 and 2.0 as well as 3.0, but at each phases the possible improvements are made. At the end of each semester a survey was conducted on ViTAS and encouraging responses had been received from the instructors and the students who are using the system. A sample of survey questions is presented in Table 7 from spring 2012 and spring 2013.

Table 7. Student survey questioner on ViTAS

\begin{tabular}{cl}
\hline Number & \multicolumn{1}{c}{ Survey Questions } \\
\hline 1 & I found it easy to access ViTAS. \\
2 & Uploading homework into ViTAS was a simple process. \\
3 & The time required to grade other students' homework was reasonable. \\
4 & Using ViTAS made me more consistent in completing homework assignments. \\
5 & Grading other students' homework enhanced my own understanding of concepts taught in this \\
6 & Ilass. \\
7 & Using ViTAS has made homework more important to me. \\
8 & How important has your use of ViTAS been to your success in this class? \\
9 & How much has the use of ViTAS added to your understanding of concepts taught in this class? \\
10 & Indicate how you felt about studying with other students BEFORE and then AFTER you used \\
\hline
\end{tabular}

Based on the survey conducted during ViTAS lifespan, it was noted that acceptance of ViTAS has been improved significantly due to the system modification. Students felt that grading their peers helped them to learn different techniques in solving problems. Also, they learned the mistakes they made by grading their peers assignments. The summary of survey results are presented in Table 8 for question 1 to 9 (see Table 8). Also, the comparison of benefit for before and after using ViTAS in different courses is presented in Table 9. In Table 9, it is observed that the more the system was improved, the more the students' collaborative learning capability was improved. 
Table 8. Student survey on ViTAS

\begin{tabular}{|c|c|c|c|c|c|c|c|}
\hline Response & $\begin{array}{c}\text { Strongly } \\
\text { Agree }\end{array}$ & Agree & $\begin{array}{l}\text { Neither } \\
\text { Agree or } \\
\text { Disagree }\end{array}$ & Disagree & $\begin{array}{l}\text { Strongly } \\
\text { Disagree }\end{array}$ & $\begin{array}{c}\text { No } \\
\text { Response }\end{array}$ & Total \\
\hline \multicolumn{8}{|c|}{ I found it easy to access ViTAS. } \\
\hline \multirow{2}{*}{ Spring 2012} & 12 & 52 & 35 & 54 & 27 & 0 & 180 \\
\hline & $6.70 \%$ & $28.90 \%$ & $19.40 \%$ & $30.00 \%$ & $15.00 \%$ & $0.00 \%$ & $100.00 \%$ \\
\hline \multirow{2}{*}{ Summer 2012} & 14 & 18 & 3 & 2 & 1 & 1 & 39 \\
\hline & $35.90 \%$ & $46.20 \%$ & $7.70 \%$ & $5.10 \%$ & $2.60 \%$ & $2.60 \%$ & $100.00 \%$ \\
\hline \multirow{2}{*}{ Fall 2012} & 109 & 130 & 28 & 27 & 18 & 0 & 312 \\
\hline & $34.90 \%$ & $41.70 \%$ & $9.00 \%$ & $8.70 \%$ & $5.80 \%$ & $0.00 \%$ & $100.00 \%$ \\
\hline \multirow{2}{*}{ Spring 2013} & 75 & 67 & 16 & 16 & 6 & 0 & 180 \\
\hline & $41.70 \%$ & $37.20 \%$ & $8.90 \%$ & $8.90 \%$ & $3.30 \%$ & $0.00 \%$ & $100.00 \%$ \\
\hline \multicolumn{8}{|c|}{ Uploading homework into ViTAS was a simple process. } \\
\hline \multirow{2}{*}{ Spring 2012} & 27 & 76 & 31 & 34 & 10 & 2 & 180 \\
\hline & $15.00 \%$ & $42.20 \%$ & $17.20 \%$ & $18.90 \%$ & $5.60 \%$ & $1.10 \%$ & $100.00 \%$ \\
\hline \multirow{2}{*}{ Summer 2012} & 17 & 12 & 4 & 4 & 2 & 0 & 39 \\
\hline & $43.60 \%$ & $30.80 \%$ & $10.30 \%$ & $10.30 \%$ & $5.10 \%$ & $0.00 \%$ & $100.00 \%$ \\
\hline \multirow{2}{*}{ Fall 2012} & 85 & 103 & 53 & 44 & 26 & 1 & 312 \\
\hline & $27.20 \%$ & $33.00 \%$ & $17.00 \%$ & $14.10 \%$ & $8.30 \%$ & $0.30 \%$ & $100.00 \%$ \\
\hline \multirow{2}{*}{ Spring 2013} & 62 & 61 & 34 & 14 & 9 & 0 & 180 \\
\hline & $34.40 \%$ & $33.90 \%$ & $18.90 \%$ & $7.80 \%$ & $5.00 \%$ & $0.00 \%$ & $100.00 \%$ \\
\hline \multicolumn{8}{|c|}{ The time required to grade other students' homework was reasonable. } \\
\hline \multirow{2}{*}{ Spring 2012} & 17 & 87 & 49 & 17 & 7 & 3 & 180 \\
\hline & $9.40 \%$ & $48.30 \%$ & $27.20 \%$ & $9.40 \%$ & $3.90 \%$ & $1.70 \%$ & $100.00 \%$ \\
\hline \multirow{2}{*}{ Summer 2012} & 18 & 15 & 4 & 2 & 0 & 0 & 39 \\
\hline & $46.20 \%$ & $38.50 \%$ & $10.30 \%$ & $5.10 \%$ & $0.00 \%$ & $0.00 \%$ & $100.00 \%$ \\
\hline \multirow{2}{*}{ Fall 2012} & 93 & 117 & 57 & 31 & 12 & 2 & 312 \\
\hline & $29.80 \%$ & $37.50 \%$ & $18.30 \%$ & $9.90 \%$ & $3.80 \%$ & $0.60 \%$ & $100.00 \%$ \\
\hline \multirow{2}{*}{ Spring 2013} & 55 & 79 & 32 & 8 & 6 & 0 & 180 \\
\hline & $30.60 \%$ & $43.90 \%$ & $17.80 \%$ & $4.40 \%$ & $3.30 \%$ & $0.00 \%$ & $100.00 \%$ \\
\hline
\end{tabular}


Table 8. Student survey on ViTAS (continued)

\begin{tabular}{|c|c|c|c|c|c|c|c|}
\hline Response & $\begin{array}{c}\text { Strongly } \\
\text { Agree }\end{array}$ & Agree & $\begin{array}{l}\text { Neither } \\
\text { Agree or } \\
\text { Disagree }\end{array}$ & Disagree & $\begin{array}{l}\text { Strongly } \\
\text { Disagree }\end{array}$ & $\begin{array}{c}\text { No } \\
\text { Response }\end{array}$ & Total \\
\hline \multicolumn{8}{|c|}{ Using ViTAS made me more consistent in completing homework assignments. } \\
\hline \multirow{2}{*}{ Spring 2012} & 15 & 48 & 47 & 38 & 29 & 3 & 180 \\
\hline & $8.30 \%$ & $26.70 \%$ & $26.10 \%$ & $21.10 \%$ & $16.10 \%$ & $1.70 \%$ & $100.00 \%$ \\
\hline \multirow{2}{*}{ Summer 2012} & 12 & 13 & 10 & 3 & 1 & 0 & 39 \\
\hline & $30.80 \%$ & $33.30 \%$ & $25.60 \%$ & $7.70 \%$ & $2.60 \%$ & $0.00 \%$ & $100.00 \%$ \\
\hline \multirow{2}{*}{ Fall 2012} & 78 & 71 & 86 & 37 & 36 & 4 & 312 \\
\hline & $25.00 \%$ & $22.80 \%$ & $27.60 \%$ & $11.90 \%$ & $11.50 \%$ & $1.30 \%$ & $100.00 \%$ \\
\hline \multirow{2}{*}{ Spring 2013} & 50 & 44 & 49 & 16 & 20 & 1 & 180 \\
\hline & $27.80 \%$ & $24.40 \%$ & $27.20 \%$ & $8.90 \%$ & $11.10 \%$ & $0.60 \%$ & $100.00 \%$ \\
\hline \multicolumn{8}{|c|}{ Grading other students' homework enhanced my own understanding of concepts taught in this class. } \\
\hline \multirow{2}{*}{ Spring 2012} & 10 & 47 & 75 & 26 & 21 & 1 & 180 \\
\hline & $5.60 \%$ & $26.10 \%$ & $41.70 \%$ & $14.40 \%$ & $11.70 \%$ & $0.60 \%$ & $100.00 \%$ \\
\hline \multirow{2}{*}{$\begin{array}{l}\text { Summer } \\
2012\end{array}$} & 9 & 11 & 13 & 5 & 1 & 0 & 39 \\
\hline & $23.10 \%$ & $28.20 \%$ & $33.30 \%$ & $12.80 \%$ & $2.60 \%$ & $0.00 \%$ & $100.00 \%$ \\
\hline \multirow{2}{*}{ Fall 2012} & 43 & 77 & 108 & 50 & 34 & 0 & 312 \\
\hline & $13.80 \%$ & $24.70 \%$ & $34.60 \%$ & $16.00 \%$ & $10.90 \%$ & $0.00 \%$ & $100.00 \%$ \\
\hline \multirow{2}{*}{ Spring 2013} & 35 & 47 & 51 & 31 & 15 & 1 & 180 \\
\hline & $19.40 \%$ & $36.10 \%$ & $28.30 \%$ & $17.20 \%$ & $8.30 \%$ & $0.60 \%$ & $100.00 \%$ \\
\hline \multicolumn{8}{|c|}{ I have spent more time on my homework because of how it is graded in ViTAS. } \\
\hline \multirow{2}{*}{ Spring 2012} & 11 & 43 & 63 & 35 & 25 & 3 & 180 \\
\hline & $6.10 \%$ & $23.90 \%$ & $35.00 \%$ & $19.40 \%$ & $13.90 \%$ & $1.70 \%$ & $100.00 \%$ \\
\hline \multirow{2}{*}{$\begin{array}{l}\text { Summer } \\
2012\end{array}$} & 7 & 8 & 16 & 5 & 3 & 0 & 39 \\
\hline & $17.90 \%$ & $20.50 \%$ & $41.00 \%$ & $12.80 \%$ & $7.70 \%$ & $0.00 \%$ & $100.00 \%$ \\
\hline \multirow{2}{*}{ Fall 2012} & 45 & 74 & 109 & 49 & 33 & 2 & 312 \\
\hline & $14.40 \%$ & $23.70 \%$ & $34.90 \%$ & $15.70 \%$ & $10.60 \%$ & $0.60 \%$ & $100.00 \%$ \\
\hline \multirow{2}{*}{ Spring 2013} & 24 & 43 & 63 & 31 & 18 & 1 & 180 \\
\hline & $13.30 \%$ & $23.90 \%$ & $35.00 \%$ & $17.20 \%$ & $10.00 \%$ & $0.60 \%$ & $100.00 \%$ \\
\hline
\end{tabular}


Table 8. Student survey on ViTAS (continued)

\begin{tabular}{|c|c|c|c|c|c|c|c|}
\hline Response & $\begin{array}{l}\text { Strongly } \\
\text { Agree }\end{array}$ & Agree & $\begin{array}{l}\text { Neither Agree } \\
\text { or Disagree }\end{array}$ & Disagree & $\begin{array}{l}\text { Strongly } \\
\text { Disagree }\end{array}$ & $\begin{array}{c}\text { No } \\
\text { Response }\end{array}$ & Total \\
\hline \multicolumn{8}{|c|}{ Using ViTAS has made homework more important to me. } \\
\hline \multirow{2}{*}{ Spring 2012} & 12 & 43 & 62 & 34 & 27 & 2 & 180 \\
\hline & $6.70 \%$ & $23.90 \%$ & $34.40 \%$ & $18.90 \%$ & $15.00 \%$ & $1.10 \%$ & $100.00 \%$ \\
\hline \multirow{2}{*}{ Summer 2012} & 8 & 8 & 17 & 3 & 3 & 0 & 39 \\
\hline & $20.50 \%$ & $20.50 \%$ & $43.60 \%$ & $7.70 \%$ & $7.70 \%$ & $0.00 \%$ & $100.00 \%$ \\
\hline \multirow{2}{*}{ Fall 2012} & 55 & 83 & 96 & 47 & 31 & 0 & 312 \\
\hline & $17.60 \%$ & $26.60 \%$ & $30.80 \%$ & $15.10 \%$ & $9.90 \%$ & $0.00 \%$ & $100.00 \%$ \\
\hline \multirow{2}{*}{ Spring 2013} & 38 & 39 & 59 & 24 & 18 & 2 & 180 \\
\hline & $21.10 \%$ & $21.70 \%$ & $32.80 \%$ & $13.30 \%$ & $10.00 \%$ & $1.10 \%$ & $100.00 \%$ \\
\hline \multicolumn{8}{|c|}{ How important has your use of ViTAS been to your success in this class? } \\
\hline \multirow{2}{*}{ Spring 2012} & 15 & 31 & 49 & 42 & 41 & 2 & 180 \\
\hline & $8.30 \%$ & $17.20 \%$ & $27.20 \%$ & $23.30 \%$ & $22.80 \%$ & $1.10 \%$ & $100.00 \%$ \\
\hline \multirow{2}{*}{ Summer 2012} & 6 & 16 & 11 & 4 & 1 & 1 & 39 \\
\hline & $15.40 \%$ & $41.00 \%$ & $28.20 \%$ & $10.30 \%$ & $2.60 \%$ & $2.60 \%$ & $100.00 \%$ \\
\hline \multirow{2}{*}{ Fall 2012} & 64 & 83 & 82 & 42 & 41 & 0 & 312 \\
\hline & $20.50 \%$ & $26.60 \%$ & $26.30 \%$ & $13.50 \%$ & $13.10 \%$ & $0.00 \%$ & $100.00 \%$ \\
\hline \multirow{2}{*}{ Spring 2013} & 25 & 62 & 57 & 20 & 16 & 0 & 180 \\
\hline & $13.90 \%$ & $34.40 \%$ & $31.70 \%$ & $11.10 \%$ & $8.90 \%$ & $0.00 \%$ & $100.00 \%$ \\
\hline
\end{tabular}

Table 9. Student survey on collaborative study before and after using ViTAS

\begin{tabular}{|l|l|l|l|c|c|c|c|}
\hline \multicolumn{7}{|c|}{ Indicate how you felt about studying with other students BEFORE and then AFTER } \\
you used ViTAS \\
\hline Semester & Response & $\begin{array}{c}\text { Very } \\
\text { valuable }\end{array}$ & Valuable & $\begin{array}{c}\text { Might } \\
\text { be } \\
\text { valuable }\end{array}$ & $\begin{array}{c}\text { Somewhat } \\
\text { valuable }\end{array}$ & $\begin{array}{c}\text { Not } \\
\text { valuable }\end{array}$ & $\begin{array}{c}\text { No } \\
\text { Response }\end{array}$ \\
\hline Spring & Before & $20.00 \%$ & $30.00 \%$ & $17.80 \%$ & $22.20 \%$ & $7.20 \%$ & $2.80 \%$ \\
\cline { 3 - 9 } & After & $17.80 \%$ & $29.40 \%$ & $18.30 \%$ & $22.80 \%$ & $8.30 \%$ & $3.30 \%$ \\
\hline Summer & Before & $23.10 \%$ & $28.20 \%$ & $10.30 \%$ & $28.20 \%$ & $10.30 \%$ & $0.00 \%$ \\
\hline $\mathbf{2 0 1 2}$ & After & $12.80 \%$ & $35.90 \%$ & $15.40 \%$ & $30.80 \%$ & $5.10 \%$ & $0.00 \%$ \\
\hline Fall & Before & $10.30 \%$ & $27.60 \%$ & $19.20 \%$ & $32.40 \%$ & $6.10 \%$ & $4.50 \%$ \\
\hline $\mathbf{2 0 1 2}$ & After & $15.70 \%$ & $30.80 \%$ & $12.20 \%$ & $26.30 \%$ & $10.60 \%$ & $4.50 \%$ \\
\hline $\begin{array}{l}\text { Spring } \\
\mathbf{2 0 1 3}\end{array}$ & Before & $20.00 \%$ & $34.40 \%$ & $11.70 \%$ & $26.70 \%$ & $1.70 \%$ & $5.60 \%$ \\
\hline & After & $23.90 \%$ & $42.80 \%$ & $6.70 \%$ & $17.80 \%$ & $3.30 \%$ & $5.60 \%$ \\
\hline
\end{tabular}




\section{Improved retention rate observed after ViTAS implementation}

The primary purpose of ViTAS application was to improve the retention rate in freshman and sophomore level students and encourage them by establishing an environment outside the class period. After implementing ViTAS and using the same set of courses, data was collected from spring 2011 to spring 2013 and a comparison of student drop rate before and after the use of ViTAS was presented in Table 10.

It can be easily observed that the drop rate significantly improved from $12.79 \%-9.87 \%$ to $4.80 \%$ $3.02 \%$ during the ViTAS implementation period. The research is still going on by collecting the data for fall 2013 to spring 2014. Moreover, ViTAS is used in several upper level courses to observe the students' performance. It was observed that the ViTAS worked better on problem based courses than writing intensive ones.

Table 10. Comparison of student drop rate before and after ViTAS

\begin{tabular}{|lccccccc|}
\hline & \multicolumn{2}{c}{ Before ViTAS } & \multicolumn{5}{c|}{ After ViTAS } \\
\hline Semester & Spring 2011 & Fall 2011 & Spring 2012 & Summer 2012 & Fall 2012 & Spring 2012 \\
\hline Enrolled & 1235 & 1428 & 229 & 72 & 453 & 265 \\
\hline Completed & 1077 & 1287 & 203 & 65 & 438 & 257 \\
\hline Dropped & 158 & 141 & 11 & 3 & 15 & 8 \\
\hline Rate (\%) & $\mathbf{1 2 . 7 9}$ & $\mathbf{9 . 8 7}$ & $\mathbf{4 . 8 0}$ & $\mathbf{4 . 1 7}$ & $\mathbf{3 . 3 1}$ & $\mathbf{3 . 0 2}$ \\
\hline
\end{tabular}

\section{Conclusion}

The objectives of this research are to improve retention rate at the freshman and sophomore level students in a minority serving institutions like _ University by implementing a web-based application for homework assignments and grading. The ViTAS is developed based on Agile system development life cycle process and this application is deployed with 1073 undergraduate STEM students and 12 graduate students throughout the academic year 2012-2013 and data are collected. Currently, the system provides a platform where the students are able to submit their homework assignments, review them, learn from their peers and communicate with the professors in an effective way. Moreover, this research provides the results that show the improvement on the student drop rate compare to the other courses which did not used ViTAS. This application was developed based on the view of Hispanic-Serving institution. It was observed throughout the lifetime of the system, that the drop rate Hispanic students were reduced significantly for those STEM courses where the ViTAS was applied. The ViTAS will require additional hardware, if it is implemented for all STEM courses.

This is an on-going research based on the learning methods that has both qualitative and quantitative measures. The quantitative measures include reduced student drop rate, course grade improvements, the growth of woman in mathematics, sciences, and engineering majors, and future research. The qualitative measures include students' interest of education mathematics, engineering, chemistry, physics, and other science courses. Also, the ViTAS can be implemented 
in different institutions and more statistical analysis can be achieved on students' learning motivation and the advantages.

\section{Acknowledgements}

The authors like to show their heartfelt gratitude to the United States Department of Education for funding support, without which this application may never be developed. Also, the authors like to thank the reviewers for their careful review to improve the quality of the paper. Also, the authors like to thank Dr. Rafic A. Bachnak, Penn State Harrisburg, Middletown, Philadelphia, Dr. Hoonandara R. Goonatilake, Dr. Eduardo Chappa, Dr. Qingwen Ni, Dr. Anju Gupta, and Ms. Teresa Nguyen of Texas A\&M International University, Laredo, Texas, and Dr. Fernando Gonzalez, Florida Gulf Coast University, Fort Myers, Florida for their support.

\section{References}

[1]. Ambler, S.W., (2011), “The Agile System Development Life Cycle (SDLC),” Ambysoft.com, retrieved August 24, 2011, from http://www.ambysoft.com/essays/agileLifecycle.html

[2]. Baillie, C., and Moore, I., Effective Learning and Teaching in Engineering, Routledge Falmer, 2004, New York, NY 10016.

[3]. Bempechat, J., (2004), “The motivational benefits of homework: A social-cognitive perspective,” Theory into Practice, 43 (3), 189-196.

[4]. Biswas, P., and Lin, R., “An Approach to Improve Students’ Retention and Class Performance using a Virtual Teaching Assistant System,” Track W266.Capstone Design Courses and Tools in support of Systems Engineering Education (Georgia World Congress Center, A305), The proceedings of $120^{\text {th }}$ ASEE Annual Conference \& Exposition, Paper \# 7817, June 23-26, 2013, Atlanta, Georgia.

[5]. Biswas, P., Lin, R., Hanumanthgari, R., and Vojjala, S. B., (2012), "Development of a Virtual Teaching Assistant System applying Agile methodology,” Track W465-Systems Engineering Education and K-12, (Grand Hyatt San Antonio, Bowie B), The proceedings of $119^{\text {th }}$ ASEE Annual Conference \& Exposition, Paper \# 3945, San Antonio, Texas.

[6]. Cohn, M., User Stories Applied: For Agile Software Development, Addison-Wesley Professional, 2004, Boston, MA 02116.

[7]. Cole, D. and Espinoza, A., (2008), "Examining the Academic Success of Latino Students in Science Technology Engineering and Mathematics (STEM) Majors,” Journal of College Student Development, 49 (4), 285-300.

[8]. Cooper, H., Lindsay, J. J., Nye, B., and Greathouse, S., (1998), "Relationships among attitudes about homework, amount of homework assigned and completed, and student achievement," Journal of Educational Psychology, 90 (1), 70-83.

[9]. Crisp, G., Nora, A. and Taggart, A., (2009), "Student Characteristics, Pre-College, College, and Environmental Factors as Predictors of Majoring in and Earning a STEM Degree: An Analysis of Students Attending a Hispanic Serving Institution,” American Educational Research Journal, 46 (4), 924-942.

[10]. Dennis, J. M., Phinney, J. S., and Chuateco, L. I., (2005), “The Role of Motivation, Parental Support, and Peer Support in the Academic Success of Ethnic Minority First-Generation College Students,” Journal of College Student Development, 46 (3), 223-236.

[11]. Eren, O., and Henderson, D. J., (2011), “Are we wasting our children's time by giving them more homework?” Economics of Education Review, 30 (5), 950-961.

[12]. Ferreira, J., Sharp, H., and Robinson, H., (2011), “User experience design and agile development: Managing cooperation through articulation work," Software Practice and Experience, 41 (9), 963-974.

[13]. Garcia, J., Amescua,A., Maria-Isabel Sanchez, M-I., and Bermon, L., (2011), "Design guidelines for software processes knowledge repository development,” Information and Software Technology, 53, 834-850. 
[14]. Gary, K., Enquobahrie, A., Ibanez, L., Cheng, P., Yaniv, Z., Cleary, K., Kokoori, S., Muffih, B., and Heidenreich, J., (2011), "Agile methods for safety-critical open source software," Software Practice and Experience, 41 (9), 945-962.

[15]. Greer, D., (2011), “Agile Software Development,” Software Practice and Experience, 41 (9), 943-944.

[16]. Gebru, M. T., Phelps, A. J., and Wulfsberg, G., (2012), "Effect of clickers versus online homework on students' long-term retention of general chemistry course material," Chemistry Education Research and Practice, 13 (3), 325-329.

[17]. Katz, I., Kaplan, A., and Buzukashvily, T., (2011), “The role of parents' motivation in students' autonomous motivation for doing homework,” Learning and Individual Differences, 21 (4), 376-386.

[18]. Lin, R., Biswas, P., Bachnak, R. A., Chappa, E-L., Goonatilake, R., and Ni, Q., "Creating Virtual Teaching Assistants to Improve Mathematics, Engineering, and Physics Curriculums," Minority Science and Engineering Improvement Program (MSEIP) Grant, Grant-Award \#P120A100020, U.S. Department of Education, Washington, D. C. 20006, Duration: August 30, 2010- August 30, 2013.

[19]. Lowes, L., Lin, P., and Wang, Y., (2007), "Studying the Effectiveness of the Discussion Forum in Online Professional Development Courses,” Journal of Interactive Online Learning, 6 (3), 181-210.

[20]. Lu, R., and Bol, L., (2007), "A Comparison of Anonymous Versus Identifiable e-Peer Review on College Student Writing Performance and the Extent of Critical Feedback," Journal of Interactive Online Learning, 6 (2), 100-115.

[21]. Martin, R. C., Agile Software Development, Principles, Patterns, and Practices, Prentice Hall, 2003, Upper Saddle River, NJ 07458.

[22]. Park, Y. J., and Bonk, C. J., (2007), "Synchronous Learning Experiences: Distance and Residential Learners' Perspectives in a Blended Graduate Course,” Journal of Interactive Online Learning, 6 (3), 245-264.

[23]. Petersen, K., and Wohlin, C., (2011), "Measuring the flow in lean software development," Software Practice and Experience, 41 (9), 975-996.

[24]. Procter, R., Rouncefield, M., Poschen, M., Lin, Y., and Voss, A., (2011), “Agile Project Management: A Case Study of a Virtual Research Environment Development Project," Computer Supported Cooperative Work, 20, 197-225.

[25]. PytlikZillig, L. M., Horn, C. A., Bruning, R., Bell, S., Liu, X. Y., Siwatu, K. O., Bodvarsson, M. C., Kim, D., and Carlson, D., (2011), "Face-to-face versus computer-mediated discussion of teaching cases: Impacts on preservice teachers' engagement, critical analyses, and self-efficacy," Contemporary Educational Psychology, 36 (4), 302-312.

[26]. Richards-Babb, M., and Jackson, J. K., (2011), "Gendered responses to online homework use in general chemistry," Chemistry Education Research and Practice, 12 (4), 409-419.

[27]. Ryan, C. S., and Hemmes, N. S., (2005), "Effects of the contingency for homework submission on homework submission and quiz performance in a college course," Journal of Applied Behavioral Analysis, 38 (1), 79 88.

[28]. Schmitz, B., and Perels, F., (2011), "Self-monitoring of self-regulation during math homework behavior using standardized diaries,” Metacognition and Learning, 6 (3), 255-273.

[29]. U.S. Census Bureau, (2013), "Hispanic Americans by the Numbers," retrieved October 17, 2013, http://www.infoplease.com/spot/hhmcensus1.html

[30]. Warschauer, M., and Healey, D., (1998), “Computers and language learning: An overview," Language Teaching, 31 (2), 57-71.

[31]. Xu, J. Z., and Wu, H. Y., (2013), "Self-Regulation of Homework Behavior: Homework Management at the Secondary School Level,” Journal of Educational Research, 106 (1), 1-13. 